Abstracta Iranicacta Iranica

Revue bibliographique pour le domaine irano-aryen

Volume 40-41 | 2019

Comptes rendus des publications de 2017-2018

\title{
Marie Favereau. La Horde d'Or et le sultanat mamelouk. Naissance d'une alliance
}

\section{Denise Aigle}

\section{(2) OpenEdition}

1 Journals

\section{Édition électronique}

URL : http://journals.openedition.org/abstractairanica/50397

DOI : 10.4000/abstractairanica.50397

ISBN : 1961-960X

ISSN : 1961-960X

Éditeur :

CNRS (UMR 7528 Mondes iraniens et indiens), Éditions de l'IFRI

Référence électronique

Denise Aigle, « Marie Favereau. La Horde d'Or et le sultanat mamelouk. Naissance d'une alliance », Abstracta Iranica [En ligne], Volume 40-41 | 2019, document 15, mis en ligne le 30 décembre 2019, consulté le 20 avril 2021. URL : http://journals.openedition.org/abstractairanica/50397 ; DOI : https:// doi.org/10.4000/abstractairanica.50397

Ce document a été généré automatiquement le 20 avril 2021.

Tous droits réservés 


\title{
Marie Favereau. La Horde d'Or et le sultanat mamelouk. Naissance d'une alliance
}

\author{
Denise Aigle
}

\section{RÉFÉRENCE}

Marie Favereau. La Horde d'Or et le sultanat mamelouk. Naissance d'une alliance. Le Caire :

IFAO, 2018, 176 p. ISBN 978-2-7247-0718-2

1 L'A. s'intéresse dans cet ouvrage aux relations entre la Horde d'Or et les Mamelouks. Elle se concentre sur une courte période (1261-1263), celle de la mise en place de l'alliance entre Baybars (r. 1260-1277), le sultan mamelouk, et Berke (r. 1257-1267), le Khan de la Horde d'Or, contre leur ennemi commun, l'Ilkhan Hülegü. L'ouvrage est constitué d'une «Introduction» (p. 1-12), de trois chapitre: "Micro-contexte», p. 13-40 ; «Vecteurs entre deux mondes », p. 41-68; «Macro-contexte», p. 69-105; et d'une «Conclusion. Sept propositions », p. 107-116.

2 La problématique originale mise en œuvre par l'auteur consiste à analyser les faits selon deux échelles d'observation afin de combiner une lecture "macro-sociale", donnant une vision d'ensemble des enjeux géopolitiques, et une lecture «microsociale » qui s'intéresse aux acteurs et à la portée de leurs décisions. En effet, il n'est pas seulement question dans cette étude « du Khan Berke, du sultan Baybars et de l'empereur Michel Paléologue, mais aussi de trois entités politiques régionales, la Horde d'or, le sultanat mamelouk et Byzance"(p.11). Le changement de focale entre « micro » et «macro » permet de tenir compte à la fois des agents matériels (lieux de rencontre, itinéraires) et humains (ambassadeurs, intermédiaires, passeurs) dans le " grand théâtre géopolitique » (p. 11) dans lequel ils se meuvent. Cette façon d'aborder l'étude de la mise en place de l'alliance entre la Horde d'Or et le sultanat mamelouk se concrétise dans le découpage du livre en trois chapitres allant du «micro-contexte » 
(les relations entre les deux acteurs de l'alliance) au «macro-contexte » qui aborde la géopolitique de l'ensemble du Proche et Moyen Orient.

Dans l'introduction, Marie Favereau montre qu'au xIII siècle, le monde musulman oriental a été soumis à un bouleversement considérable suite à l'invasion mongole qui a vu l'émergence de plusieurs entités politiques nouvelles. La diplomatie des Mamelouks, comme le souligne Marie Favereau, a été essentiellement étudié dans le cadre de leurs relations avec les Francs, les Byzantins et les Ilkhans. Cette recherche est la première étude sur les échanges diplomatiques entre les Mamelouks et la Horde d'Or. La période choisie (660/1261-662/1264) est fondatrice pour les deux entités politiques car elle correspond à la « construction d'une première légitimité d'empire » (p. 9).

Dans le chapitre 1 "Micro-contexte", Marie Favereau retrace la chronologie des différentes ambassades et les modalités d'accueil des émissaires. L'alliance impliquait de nombreux acteurs qui travaillaient dans l'ombre. Ils font l'objet du chapitre 2 « Vecteurs entre deux mondes ». Ces derniers ont des profils très variés : traducteurs, grands marchands, hommes de religion, militaires. Les ambassadeurs qui n'étaient pas choisis de manière anodine, étaient sélectionnés en fonction de l'objectif recherché. La première ambassade que Baybars envoya à Berke en 1262 était composée d'un émir turc d'Asie centrale, en raison de sa connaissance des langues, de deux wāfidūn («immigrés », "venus de l'extérieur »), c'est-à-dire des Jochides réfugiés dans le sultanat mamelouk donc des proches du Khan de la Horde d'Or, et d'un juriste, pour que l'accord soit conclu dans le cadre de l'islam. Les marchands alains faisaient également partie des ambassades à cause de leur rôle dans l'acheminement des esclaves dans le sultanat mamelouk. Enfin, les wāfidūn participaient à la rédaction des lettres et étaient chargés de délivrer des messages oraux. On sait par ailleurs que des femmes mongoles accompagnaient les wäfidūn. Elles épousèrent des émirs mamelouks et furent sans doute l'un des vecteurs d'une transmission culturelle entre la Horde d'or et le sultanat mamelouk. Marie Favereau aborde également un autre aspect important dans les échanges diplomatiques, celui des cadeaux. Ils avaient "une fonction dans l'économie des élites » (p. 61) et, comme le souligne Marie Favereau, la fonction ultime des cadeaux exigeait implicitement une contrepartie équivalente. Le chapitre 3 « Macro-contexte » étudie l'ensemble des acteurs qui participèrent à l'alliance entre le sultanat mamelouk et la Horde d'Or, tout en portant aussi attention à la situation interne à l'Empire mongol. L'auteur souligne à juste titre que dans l'historiographie seule la position du sultan a été prise en compte par les chercheurs, mais que celle du Khan n'a pas été clairement explicitée. Elle explique que face à la montée en puissance de Hülegü, Berke a fait le choix radical d'asseoir son pouvoir sur de nouvelles bases en faisant de la Horde d'Or une entité indépendant au sein de l'empire gengiskhanide. Byzance était un autre acteur important dans cette politique régionale. L'envoi de la première lettre au khan à la suite d'un échange de lettres et de cadeaux avec Michel Paléologue ne fut pas le fruit du hasard (p. 83). Il ne s'agissait pas simplement d'un pacte de non-agression et de soutien réciproque, des accords de conversion monétaire avaient sans doute été signés afin de faciliter les échanges commerciaux entre les domaines mamelouks, byzantins et jochides. Dense en informations, ce chapitre permet de comprendre quels étaient les objectifs des différents acteurs. Dans une conclusion très synthétique (p.107-116), Marie Favereau tire les principaux enseignements de cette alliance. On a souvent considéré qu'elle n'était qu'une simple entente cordiale, mais elle était à vrai dire essentielle aux deux parties. On a considéré que l'islam n'a pas été le facteur décisif. Néanmoins, Marie Favereau montre que les cadeaux de Baybars à 
Berke sont révélateurs du rôle central que l'un et l'autre accordaient aux institutions de l'islam. Autre idée souvent avancée, le conflit d'autorité en Transcaucasie aurait été le facteur qui aurait déclenché la guerre entre Berke et Hülegü. Analyse aussi contredite par l'ouvrage de Marie Favereau qui montre que la guerre n'était pas territoriale mais qu'elle visait à contrôler les ressources commerciales et fiscales. Baybars aurait été en position de vassal face à l'idéologie impériale gengiskhanide, mais à vrai dire trois puissances (Jochides, Mamelouks et Byzantins) étaient impliquées dans cette alliance pour des motifs différents, mais toutes les trois en avaient besoin. Par ailleurs, l'alliance tripartite entre Mamelouks, Byzance et Jochides et le combat de Hülegü contre Berke ouvrirent la mer Noire à la concurrence des marchands, notamment génois. Enfin, selon Marie Favereau l'alliance ne fut pas un fiasco car le nœud de celle-ci était la mise sous contrôle des ressources et des circulations des biens, des bêtes et des hommes. Les Jochides ne parvinrent sans doute pas de reprendre la main dans le pays de Rūm, mais s'ils s'imposèrent désormais aux Byzantins comme une puissance qui disposait d'un droit de passage par les détroits, et qui ne fut pas remis en question par les Ottomans au XV $v^{\mathrm{e}}$ siècle.

5 Un récapitulatif chronologique, de très utiles annexes sous forme de tableaux, des extraits de textes traduits, un glossaire, une bibliographie, un index et 4 cartes, indispensables pour situer le déroulement des événements et le déplacement des acteurs dans l'espace complètent (p.117-176) complètent cet ouvrage très novateur dans sa démarche et son approche des faits politiques. Cette courte période chronologique (1261-1263) fut fondatrice pour l'émergence de la politique diplomatique de la Horde d'Or avec les autres puissances régionales.

\section{AUTEURS}

\section{DENISE AIGLE}

UMR 8167 - Orient et Méditerranée 